\title{
Explicit Representation of Subgrid Heterogeneity in a GCM Land Surface Scheme
}

\author{
R. L. H. Essery, M. J. Best, R. A. Betts, And P. M. Cox \\ Met Office, Hadley Centre for Climate Prediction and Research, Bracknell, United Kingdom \\ C. M. TAYLOR \\ Centre for Ecology and Hydrology, Wallingford, United Kingdom
}

(Manuscript received 14 December 2001, in final form 6 November 2002)

\section{ABSTRACT}

\begin{abstract}
A land surface scheme that may be run with or without a tiled representation of subgrid heterogeneity and includes an implicit atmospheric coupling scheme is described. Simulated average surface air temperatures and diurnal temperature ranges in a GCM using this surface model are compared with climatology. Surface tiling is not found to give a clear improvement in the simulated climate but offers more flexibility in the representation of heterogeneous land surface processes. Using the same meteorological forcing in offline simulations using versions of the surface model with and without tiling, the tiled model gives slightly lower winter temperatures at high latitudes and higher summer temperatures at midlatitudes. When the surface model is coupled to a GCM, reduced evaporation in the tiled version leads to changes in cloud cover and radiation at the surface that enhance these differences.
\end{abstract}

\section{Introduction}

Land surface models, which calculate exchanges of heat, moisture, momentum, and $\mathrm{CO}_{2}$ between the surface and the atmosphere, are important elements of the general circulation models (GCMs) used in climate modeling and numerical weather prediction. With resolution constrained by computational expense, GCM gridboxes cover large areas; a single land gridbox will almost invariably contain surfaces with widely varying characteristics, possibly leading to large subgrid variations in surface temperatures and fluxes. Most current GCMs assume that land surface properties such as albedo, roughness length, and moisture conductance can be characterized by effective parameters; the Met Office Surface Exchange Scheme (MOSES; Cox et al. 1999), recently developed for use in the Met Office GCM, is in this category. Gridbox-average fluxes of sensible heat, moisture, and momentum are calculated from gridbox-average vertical gradients of temperature, humidity, and wind speed using parameterizations similar to those used to relate local fluxes to local gradients over homogeneous surfaces. Local fluxes, however, depend nonlinearly on local gradients, and average fluxes may not be simply related to average gradients. It has been suggested that the problem of calculating gridbox-av-

Corresponding author address: Richard Essery, Institute of Geography and Earth Sciences, University of Wales, Aberystwyth SY23 3DB, United Kingdom.

E-mail: richard.essery@aber.ac.uk erage fluxes can be addressed by gathering distinct surface types within a gridbox into homogeneous "tiles" in a "mosaic" (Avissar and Pielke 1989; Koster and Suarez 1992b). Surface temperatures and fluxes are calculated using parameters characteristic of each surface type; average fluxes are then found by summing the fluxes from the tiles, weighted by the fractional areas that they cover. The performance of tile models has been investigated in many offline studies (Koster and Suarez 1992a; Desborough 1999; van den Hurk et al. 2000; Molod and Salmun 2002) and boundary layer or mesoscale atmospheric models (Avissar and Pielke 1989; Claussen 1991; Klink 1995; Blyth 1995; Mölders et al. 1996; Essery 1997). Although tile models have been implemented in several GCMs (Verseghy et al. 1993; Koster and Suarez 1996; Desborough et al. 2001), their influence on simulated climates has not yet been widely reported. In this paper, we discuss a version of MOSES, designated MOSES 2, that includes a tile model of surface heterogeneity and a new numerical scheme for coupling between the land surface and the atmosphere. MOSES 2 is described and contrasted with the original MOSES in section 2, and results of climate simulations are presented in section 3 .

To assess the impact of surface tiling, MOSES 2 is run in both tiled and aggregated modes. In the aggregated model, resistances for different surface types are added in parallel before being used in single surface energy and moisture budgets for each gridbox. The tiled and aggregated versions of MOSES 2 are thus equiv- 
alent to the "mosaic" and "mixture" strategies of Koster and Suarez (1992a), who derived analytical and numerical solutions for these modeling strategies in a restricted range of circumstances. They concluded that an aggregate model produces more evaporation and lower average surface temperatures, but the differences are small in most conditions. Running global offline simulations produces similar results, except that the aggregate model can produce higher surface temperatures than the tile model for gridboxes with large subgrid contrasts in albedo, a situation not explored by Koster and Suarez (1992a). Desborough (1999) found monthly evaporation to be largely insensitive to the introduction of separate energy balances for vegetated and nonvegetated fractions of the surface in offline simulations. Desborough et al. (2001), however, found a much larger sensitivity when the same surface model was coupled to a GCM; they attributed this to differences in calibration between the offline and coupled simulations. We find larger differences between the tile and aggregate models when coupled to the GCM even when the same surface parameters are used in offline and coupled simulations, and we show this to be due to feedbacks through the atmosphere.

\section{Model description}

\section{a. Surface parameters}

In MOSES, a set of surface parameters was assigned to each of the 23 classes in the Wilson and HendersonSellers (1985) $1^{\circ} \times 1^{\circ}$ land cover archive and aggregated at the GCM resolution of $2.5^{\circ}$ latitude by $3.75^{\circ}$ longitude. MOSES 2, in contrast, was designed to complement the Top-Down Representation of Interactive Foliage and Flora Including Dynamics (TRIFFID) vegetation dynamics model (Cox et al. 2000; Cox 2001) and so represents each gridbox as a mixture of the five TRIFFID vegetation types (broadleaf trees, needleleaf trees, temperature $\mathrm{C}_{3}$ grass, tropical $\mathrm{C}_{4}$ grass, and shrubs) and four nonvegetated surface types (urban, inland water, soil, and ice). Vegetation distributions may be obtained from observations or modeled by TRIFFID; this study uses a University of Maryland dataset with 14 land cover classes at $1-\mathrm{km}$ resolution derived from Advanced Very High Resolution Radiometer (AVHRR) data (Hansen et al. 2000). Mappings between these classes and assumed fractions of the MOSES 2 surface types are given in Table 1; grasses were partitioned into $\mathrm{C}_{3}$ and $\mathrm{C}_{4}$ types using a function of latitude.

A leaf area index $L$ for each vegetation tile is read from maps based on those used by the second Simple Biosphere Model (SiB2; Sellers et al. 1996a), again derived from AVHRR data. Seasonal variations in $L$ for deciduous trees are calculated by a leaf phenology model (Cox 2001). Vegetation tiles are assigned a canopy height $h$, a snow-free roughness length $z_{o}$, and a canopy water capacity $C_{M}$ parameterized as functions of $L$ (Es- sery et al. 2001). Evaporation from transpiring vegetation is controlled by canopy conductance, $g_{c}$, calculated by a photosynthesis model (Cox et al. 1998; Cox 2001) which depends on temperature, humidity deficit, incident radiation, soil moisture availability, and vegetation type. The ability of vegetation to access moisture at each level in the soil is determined by a root density distribution; in place of the uniform distribution in MOSES, root density is assumed to follow an exponential distribution with depth (Thornley and Johnson 1990).

For each nonvegetated tile, a snow-free albedo and a roughness length are specified; albedos for bare soil depend on the soil color as specified by Wilson and Henderson-Sellers (1985). Bare-soil evaporation is drawn from the surface soil layer only. Lakes and urban surfaces cover relatively small fractions of gridboxes at GCM resolution and are very simply represented: lake tiles are smooth and wet; urban tiles are rough and have a small surface water capacity. More sophisticated representations are being considered for higher-resolution applications.

\section{b. Surface net radiation}

MOSES used a single albedo for each gridbox and for all spectral bands. Albedos for gridboxes with snow cover were interpolated between specified snow-free and deep-snow values, with snow aging represented by a simple linear function of surface temperature (Cox et al. 1999). In MOSES 2, separate direct-beam and diffuse albedos in visible and near-infrared bands are used for each tile. Vegetation albedos are calculated using the Sellers (1985) canopy radiative transfer model with spherical leaf distributions, and snow albedos are calculated using the Marshall (1989) parameterization of the Wiscombe and Warren (1980) spectral albedo model, in which the albedo depends on a prognostic snow grain size that increases with the age of the snow surface. Snow-free tile albedos and snow albedos are weighted by a fraction,

$$
f_{s}=\frac{d}{d+10 z_{o}},
$$

to give an albedo $\alpha=f_{s} \alpha_{s}+\left(1-f_{s}\right) \alpha_{o}$ for a tile with snow depth $d$, deep-snow albedo $\alpha_{s}$, and snow-free albedo $\alpha_{o}$. A forest tile with snow cover is thus given a lower albedo than a smoother tile with the same depth of snow but smaller $z_{o}$ (Pomeroy and Dion 1996; Viterbo and Betts 1999; Betts 2000).

For downward shortwave and longwave radiation fluxes $S W \downarrow$ and $L W \downarrow$, the net radiation absorbed by a tile with surface temperature $T_{*}$ is

$$
R_{N}=\sum_{i}\left(1-\alpha_{i}\right) \mathrm{SW}_{\downarrow i}+\mathrm{LW}_{\downarrow}-\sigma T_{*}^{4},
$$

where the summation is over shortwave bands and $\alpha$ is the Stefan-Boltzmann constant. All surfaces are as- 
TABLE 1. Mappings between Hansen et al. (2000) land cover classes and fractions of MOSES 2 surface types. Note, BLT $=$ broadleaf trees and NLT $=$ needleleaf trees.

\begin{tabular}{|c|c|c|c|c|c|c|c|}
\hline & BLT & NLT & Grass & Shrub & Urban & Water & Soil \\
\hline Water bodies & & & & & & 1 & \\
\hline Evergreen needleleaf forest & & 0.8 & 0.05 & & & & 0.15 \\
\hline Evergreen broadleaf forest & 0.9 & & & & & & 0.1 \\
\hline Deciduous needleleaf forest & & 0.8 & 0.05 & & & & 0.15 \\
\hline Deciduous broadleaf forest & 0.8 & & 0.15 & & & & 0.05 \\
\hline Mixed forest & 0.4 & 0.4 & 0.1 & & & & 0.1 \\
\hline Woodland & 0.45 & & 0.5 & & & & 0.05 \\
\hline Wooded grassland & 0.2 & & 0.75 & & & & 0.05 \\
\hline Closed shrubland & & & 0.15 & 0.7 & & & 0.15 \\
\hline Open shrubland & & & 0.35 & 0.35 & & & 0.3 \\
\hline Grassland & & & 0.9 & & & & 0.1 \\
\hline Cropland & & & 0.8 & & & & 0.2 \\
\hline Bare ground & & & & & & & 1 \\
\hline Urban and built-up & & & & & 1 & & \\
\hline
\end{tabular}

sumed to have unit emissivity. Linearizing about surface soil layer temperature $T_{s}$ gives

$$
R_{N} \approx R_{s}+4 \sigma T_{s}^{3}\left(T_{s}-T_{*}\right)
$$

with

$$
R_{s}=\sum_{i}\left(1-\alpha_{i}\right) \mathrm{SW}_{\downarrow i}+\mathrm{LW}_{\downarrow}-\sigma T_{s}^{4}
$$

\section{c. Surface heat and moisture fluxes}

Given temperature $T_{1}$ and specific humidity $q_{1}$ at reference height $z_{1}$ in the atmosphere, expressions for surface fluxes of sensible heat $H$ and moisture $E$ over each tile are derived from the bulk aerodynamic formulas

$$
\begin{aligned}
& H=c_{p} \frac{\rho}{r_{a}}\left(T_{*}-T_{1}-\frac{g z_{1}}{c_{p}}\right) \text { and } \\
& E=\psi \frac{\rho}{r_{a}}\left[q_{\mathrm{sat}}\left(T_{*}, p_{*}\right)-q_{1}\right],
\end{aligned}
$$

respectively, where $\rho$ and $c_{p}$ are the density and heat capacity of air, $g$ is the gravitational acceleration, $r_{a}$ is an aerodynamic resistance, $T_{*}$ is the tile surface temperature, and $q_{\mathrm{sat}}\left(T_{*}, p_{*}\right)$ is the saturation humidity at temperature $T_{*}$ and surface pressure $p_{*}$. The factor $\psi$ in Eq. (6) is set to 1 for saturated surfaces (snow, ice, and water), giving evaporation at the potential rate, but otherwise is

$$
\psi=f_{a}+\left(1-f_{a}\right) \frac{g_{c}}{g_{c}+r_{a}^{-1}},
$$

assuming a fraction $f_{a}=C / C_{M}$ of the surface to be saturated for a tile with canopy moisture $C$ and capacity $C_{M}$. The aerodynamic resistance is calculated as a function of surface roughness, wind speed, and atmospheric stability through a Richardson number formulation (Louis 1979).

Although surface temperatures and parameters differ between tiles within a gridbox, $T_{1}, q_{1}$, and the wind speed at height $z_{1}$ are assumed to be homogeneous. In principle, $z_{1}$ should be set to the "blending height" (Mason 1988; Claussen 1991; Wood and Mason 1991); this is an approximate height scale high enough above the surface that the temperature, humidity, and wind speed are nearly homogeneous but low enough that their profiles are nearly in equilibrium with the local surface. Blending heights depend on surface roughness, atmospheric stability, and heterogeneity length scales; as an example, values calculated from the Institute of Terrestrial Ecology 25-m land use map of the United Kingdom range between 5 and $30 \mathrm{~m}$ (P. Hopwood 2001, personal communication). At present, MOSES 2 simply sets $z_{1}$ to the height of the lowest atmospheric level in the GCM (typically around $25 \mathrm{~m}$ above the surface), but the high resolution of the AVHRR land cover data will allow information on subgrid heterogeneity length scales to be used in the future. Extensions to the tile model concept for blending heights lying below and above the lowest model level are discussed by Blyth (1995) and Arola (1999).

Precipitation is applied uniformly to the tiles within a gridbox, although an assumed subgrid distribution of precipitation could be used. The method used for partitioning precipitation into interception by vegetation canopies, throughfall, runoff, and infiltration is unchanged from MOSES (Dolman and Gregory 1992) but is applied separately on each tile. MOSES 2 uses the same model for vertical transfers of heat and moisture and phase changes in the soil as MOSES (Cox et al. 1999) but replaces the explicit numerical solution with an implicit scheme (Essery et al. 2001); this improves the stability of the model and allows greater flexibility in the choice of model levels. By default, four soil layers with thicknesses of $0.1,0.25,0.65$, and $2 \mathrm{~m}$ are used. The heat flux $G$ from the surface into the top soil layer is parameterized as

$$
G=\frac{2 \lambda}{\Delta z_{s}}\left(T_{*}-T_{s}\right),
$$


where $\Delta z_{s}$ is the thickness of the layer, and the thermal conductivity $\lambda$ depends on soil type, moisture content, and snow depth (Cox et al. 1999). The temperature and moisture content of each subsurface layer are assumed to be homogeneous across a gridbox, but a representation of subgrid hydrology using the rainfall runoff model TOPMODEL (Beven 1997) is being considered for future use (N. Gedney 2001, personal communication).

\section{d. Surface energy balance}

Surface temperature $T_{*}$ is taken to be the skin temperature of an infinitesimal surface layer. The energy balance of this layer is

$$
R_{N}-H-\mathrm{LE}-G-L_{f} S_{M}=0,
$$

where $L$ is the latent heat of condensation $\left(L_{c}\right)$ for an unfrozen surface or of sublimation $\left(L_{\mathrm{s}}\right)$ for snow or ice, $L_{f}$ is the latent heat of fusion, and $S_{M}$ is the rate of surface snowmelt. When directed downward, $R_{N}$ and $G$ are defined to be positive, while $H$ and $E$ are positive upward. The optional inclusion of a canopy heat capacity for vegetated tiles is discussed by Essery et al. (2001).

Substituting Eqs. (3) and (8) in Eq. (9), the surface temperature is diagnosed as

$$
T_{*}=T_{s}+\frac{1}{A_{*}}\left(R_{s}-H-\mathrm{LE}-L_{f} S_{M}\right),
$$

with

$$
A_{*}=\frac{2 \lambda}{\Delta z_{s}}+4 \sigma T_{s}^{3} .
$$

Linearizing $q_{\text {sat }}$ about $T_{1}$ and using Eq. (10) to eliminate $T_{*}$ from Eqs. (5) and (6) then gives

$$
\begin{aligned}
& H=c_{p} \frac{\rho}{r_{a}}\left[\frac{\tilde{R}-L_{f} S_{M}-L \psi\left(\rho / r_{a}\right) \Delta q_{1}}{\left(c_{p}+\mathrm{LD} \psi\right) \rho / r_{a}+A_{*}}\right] \text { and } \\
& E=\psi \frac{\rho}{r_{a}}\left[\frac{D\left(\tilde{R}-L_{f} S_{M}\right)+\left(c_{p} \rho / r_{a}+A_{*}\right) \Delta q_{1}}{\left(c_{p}+\mathrm{LD} \psi\right) \rho / r_{a}+A_{*}}\right],
\end{aligned}
$$

where

$$
\begin{aligned}
D & =\left.\frac{d q_{\mathrm{sat}}}{d T}\right|_{T=T_{1}}, \\
\Delta q_{1} & =q_{\mathrm{sat}}\left(T_{1}, p_{*}\right)-q_{1}+D \frac{g z_{1}}{c_{p}}, \text { and } \\
\tilde{R} & =R_{s}-A_{*}\left(T_{1}-T_{S}+\frac{g z_{1}}{c_{p}}\right) .
\end{aligned}
$$

For tiles with snow cover, setting $S_{M}=0$ in Eqs. (10), (12), and (13) gives a first estimate for the surface temperature. Snow is melted if this exceeds the melting point $T_{m}$. The melt rate is calculated from the heat flux required to set $T_{*}=T_{m}$ or exhaust the available snow, whichever is smaller. Similar adjustments are made if the initial evaporation estimate exceeds the canopy or soil moisture stores for snow-free tiles.

\section{e. Boundary layer fluxes and increments}

The GCM's boundary layer scheme calculates the increment in the temperature of the lowest atmospheric model layer over a time step $\delta t$ as

$$
\delta T_{1}=\frac{\delta t}{c_{p} z_{1}}\left(\bar{H}-H_{1}\right),
$$

where $H_{1}$ is the heat flux at the top of the layer and

$$
\bar{H}=\sum_{j} \nu_{j} H_{j}
$$

is the surface sensible heat flux averaged over tiles with fractions $\nu_{j}$ and local fluxes $H_{j}$. Similar equations give temperature and humidity increments for all model levels in the boundary layer. An implicit numerical scheme is used in which fluxes are calculated from weighted time-step-average temperatures,

$$
T=T^{(n)}+\gamma \delta T,
$$

and humidities, where $T^{(n)}$ is the temperature of a layer at the beginning of the time step and $\gamma$ is set to 2 (Girard and Delage 1990). Substitution in Eq. (12) gives an equation of the form

$$
\bar{H}=\sum_{j} \nu_{j} H_{j}^{(n)}+A_{1} \delta T_{1}+B_{1} \delta q_{1},
$$

where $H_{j}^{(n)}$ is the "explicit" flux calculated using $T_{1}^{(n)}$ and $q_{1}^{(n)}$. The complete set of equations for boundary layer temperature and humidity increments forms a tridiagonal system, solved by Gaussian elimination; details are given by Essery et al. (2001).

In coupling MOSES 2 to the GCM, a split boundary layer scheme has been introduced following the recommendations of Polcher et al. (1998). A downward sweep through the atmospheric matrix gives expressions for $\delta T_{1}$ and $\delta q_{1}$ in terms of the gridbox-average fluxes $\bar{H}$ and $\bar{E}$. These are combined with Eq. (20) for $\bar{H}$ and the equivalent expression for $\bar{E}$ to obtain a set of equations that can be solved for $\delta T_{1}, \delta q_{1}, \bar{H}$, and $\bar{E}$. The implicit values of the fluxes and surface temperatures on each tile are then diagnosed, and back substitution in the matrix gives increments at all boundary layer levels.

\section{Results \\ a. Comparisons with climatology}

An initial test of MOSES 2 coupled to the Third Hadley Centre Atmospheric GCM (HadAM3; Pope et al. 2000) gave some large errors; summer temperatures at northern midlatitudes were too high, and July and August had excessive diurnal temperature ranges in 
southern Europe. Comparisons with fields of downward shortwave radiation derived for the International Satellite Land Surface Climatology Project (ISLSCP; Sellers et al. 1996b) showed that the spatial and temporal distributions of these temperatures errors were closely associated with excess solar radiation at the surface, a common feature of GCMs (Wild et al. 1995; Wild 2000). Excessive radiative forcing in the surface energy balance is inconvenient for our current focus, assessment of the model's near-surface temperature climatology. Thus the GCM's cloud cover was artificially increased by using random overlapping of clouds in different model layers; the standard scheme used in the initial simulation maximally overlaps clouds in contiguous layers. Considerable effort has been put into improving the representations of cloud and aerosol radiative properties for future versions of the GCM (Cusack et al. 1998, 1999; Webb et al. 2001), and results from recent modeling and observational studies (Barker et al. 1999; Hogan and Illingworth 2000) will allow the development of improved representations of vertical cloud distributions. Although less physical, a simple increase in cloud cover still improved the simulation of surface shortwave radiation. Not all of the impacts were beneficial; a reduction in tropical convective precipitation, for example, worsened the agreement with observations. The reduction in shortwave radiation did, however, improve the simulation of summer temperatures over North America and Europe, and decreased the excessive European temperature range.

The tiled version of MOSES 2 and the modified GCM were run for $15 \mathrm{yr}$ with sea surface temperatures and sea ice extents prescribed from climatology. The first 5 $\mathrm{yr}$ of the simulation were discarded to allow for spinup of deep soil temperatures and moisture contents. In Fig. 1 average surface air temperatures for DJF and JJA seasons over the last $10 \mathrm{yr}$ are compared with the Climate Research Unit 1961-90 climatology (New et al. 1999); positive values indicate areas in which the model results are warmer than the climatology. Differences between the model and climatology are smaller in summer than in winter, with the simulation generally showing a cold bias. Similar patterns in simulations using MOSES were related to errors in low-level advection by Pope et al. (2000), but the cold biases are smaller than in the earlier versions of the GCM that did not include latent heat release by freezing of soil moisture (Cox et al. 1999). It should be noted that the station network used in deriving the climatology is very sparse in some areas, such as northern high latitudes and the Himalayan plateau, where the model and the climatology differ. Covey et al. (2002) have estimated the uncertainty in observed climatologies by comparing different datasets.

Annual cycles of average temperature and diurnal temperature range over land within the boxes marked on Fig. 1 are shown in Figs. 2 and 3; the climatology is shown by solid lines, and GCM averages are shown by circles. The largest discrepancies in simulated temperature ranges are underestimates over North America and an excessive seasonal variation for the Sahel. Average minimum temperatures over Canada and the United States (not shown) appear to be well simulated, but underestimation of daytime maximum temperatures during winter leads to the underestimates in both temperature range and average temperature. Taylor and Clark (2001) found that Sahel temperature and precipitation simulations could be improved by using a better characterization of surface parameters in that region.

\section{b. Characterization of subgrid heterogeneity}

Surface temperatures and fluxes differ between tiles within a gridbox because of differences in their albedos, roughness lengths, and moisture conductances. Particularly large differences can be expected between forests and bare ground because the greater roughness of forests gives a closer coupling to the air temperature, trees can access deep soil moisture when bare-soil evaporation is limited by moisture deficits near the surface, and forests retain low albedos when snow covered. Figure 4 shows differences between forest and bare-ground surface temperatures within gridboxes, averaged over the month of March from one year of the simulation. Bare ground is generally warmer than forests at low latitudes with high surface temperatures but is colder in snow-covered regions, the temperature difference changing sign close to the $0^{\circ} \mathrm{C}$ isotherm. Albedo contrasts have less influence at high latitudes with low insolation, but temperature differences are maintained because bare ground also receives less sensible heat from the atmosphere to offset radiative cooling under stable conditions.

The subgrid variability of surface temperatures can be characterized by the standard deviation

$$
\sigma_{T}=\left[\sum_{j} \nu_{j} T_{* j}^{2}-\left(\sum_{j} \nu_{j} T_{*_{j}}\right)^{2}\right]^{1 / 2},
$$

which is plotted in Fig. 5a for July. Areas of high temperature variability reflecting large evaporation differences between surface types with different root depths in the western United States, southern Africa, and continental midlatitudes over Asia correspond with fractional surface soil layer moisture deficits, shown in Fig. 5b. Although the Sahara also has a large soil moisture deficit, the subgrid temperature variability is small on account of the lack of vegetation. In March, as shown in Fig. 6, dry-season soil moisture deficits cause increased temperature variability in the Sahel, India, and Thailand. Snow-covered land, delimited by the $10 \mathrm{~kg}$ $\mathrm{m}^{-2}$ contour line in Fig. 6a, also has large temperature contrasts between tiles because of albedo contrasts between tall vegetation, short vegetation, and bare ground with snow cover.

Spatial variances of temperatures and fluxes are re- 

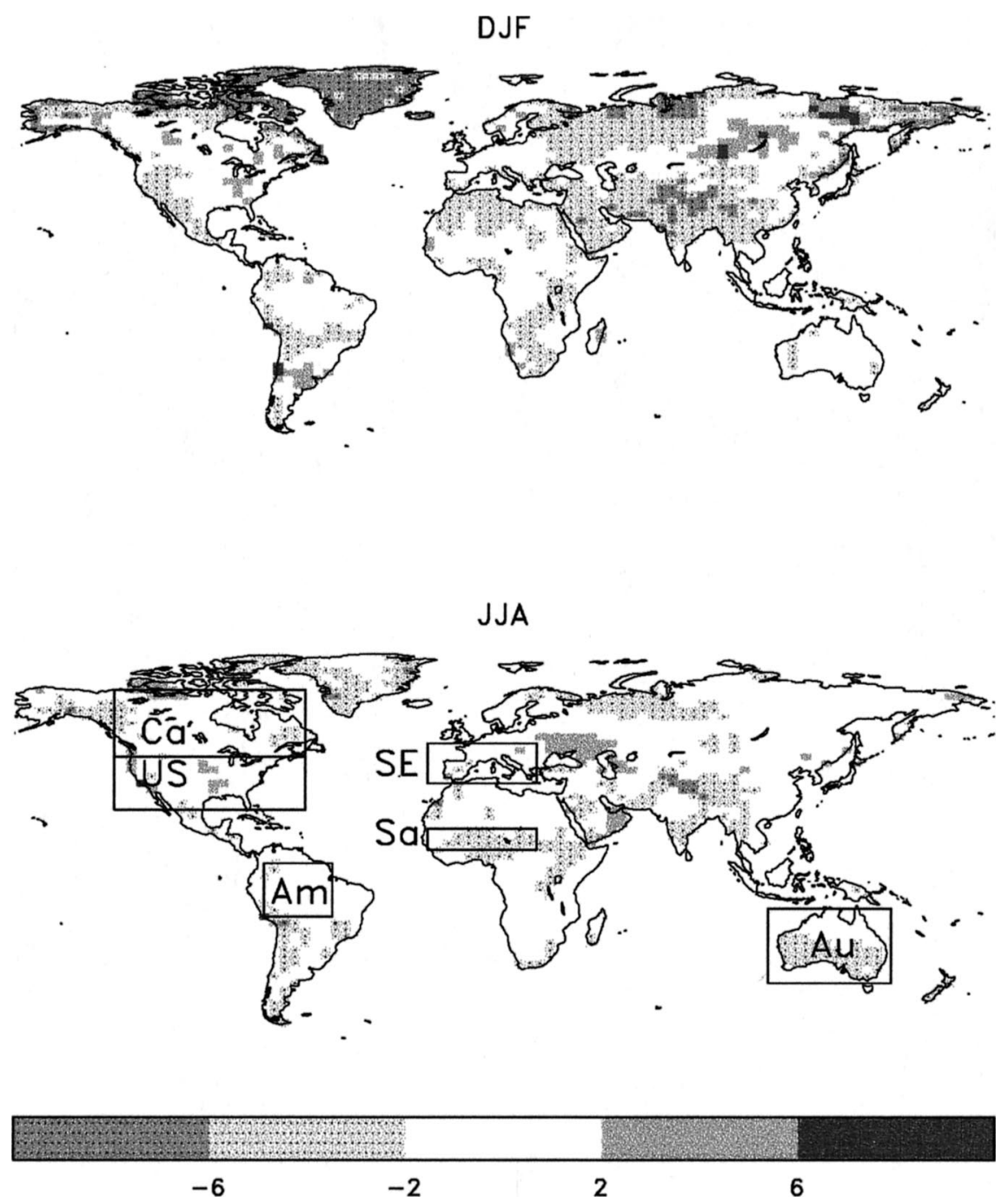

FIG. 1. Differences $\left({ }^{\circ} \mathrm{C}\right)$ between 10-yr mean simulated temperatures and climatology for DJF and JJA seasons. Positive values indicate gridboxes in which the simulation is warmer. Results in Figs. 2 and 3 are averages over land points within the areas labeled "Ca" (Canada), "US" (USA), "Am" (Amazon), "SE" (southern Europe), "Sa" (Sahel), and "Au" (Australia).

lated through Eq. (10). Using Eq. (4) for $R_{\mathrm{s}}$ and neglecting snowmelt, taking the variance of Eq. (10) gives

$$
\begin{aligned}
A_{*}^{2} \sigma_{T}^{2}= & \mathrm{SW}_{\downarrow}^{2} \sigma_{\alpha}^{2}+\sigma_{H}^{2}+\sigma_{\mathrm{LE}}^{2} \\
& -2 \mathrm{SW}_{\downarrow}[\operatorname{cov}(\alpha, H)+\operatorname{cov}(\alpha, \mathrm{LE})] \\
& -2 \operatorname{cov}(H, \mathrm{LE}),
\end{aligned}
$$

where $\alpha$ is the effective tile albedo and cov denotes the covariance of two fields. Contrasts in the turbulent fluxes dominate for snow-free land, but the radiative term becomes important for snow-covered gridboxes when $\mathrm{SW} \downarrow$ is large.

\section{c. Influence of subgrid heterogeneity}

As described in section 2, MOSES 2 differs from MOSES in a number of ways other than the surface tiling, so a gridbox-aggregate version of MOSES 2 was developed to isolate the influence of tiling. In this version, surface parameters are still calculated separately for each surface type within a gridbox but are aggregated as in MOSES before being used in calculating surface fluxes. Surface albedos, moisture capacities, and conductances are simply area averaged. Roughness lengths are aggregated at the reference height using the method of Mason (1988) to give

$$
z_{o}=z_{1} \exp \left\{-\left[\sum_{j} \frac{\nu_{j}}{\ln ^{2}\left(z_{1} / z_{o j}\right)}\right]^{-1 / 2}\right\} .
$$

This is equivalent to adding aerodynamic resistances for neutral stability in parallel.

Many investigations of tile model behavior have been performed offline, that is, using prescribed air temperatures, humidities, wind speeds, radiative fluxes, and 

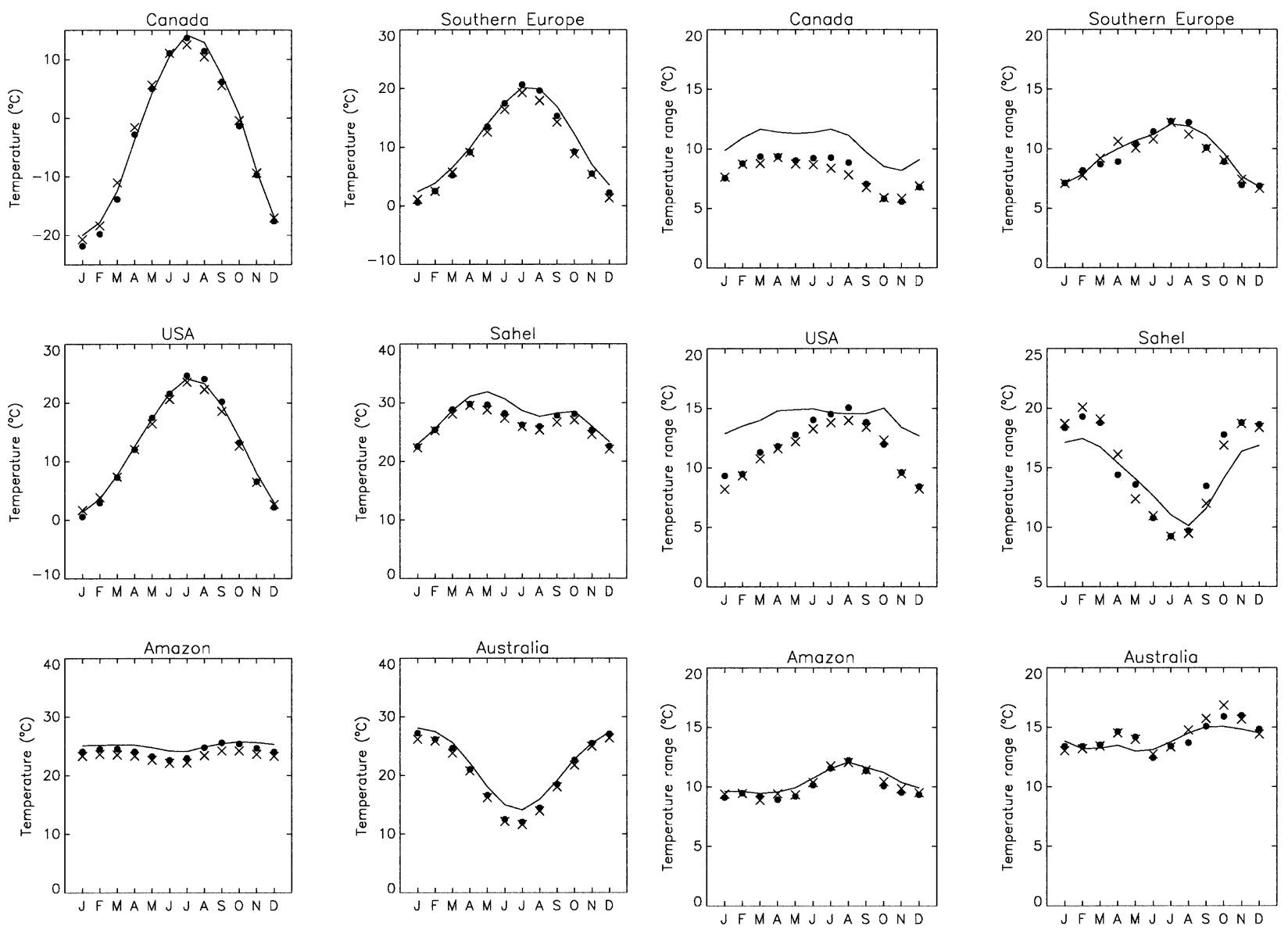

FIG. 2. Simulated surface air temperatures (filled circles) compared with climatology (lines) for the regions shown in Fig. 1. Crosses FIG. 3. As in Fig. 2, but for diurnal temperature range. show results from a simulation with aggregated surface parameters.

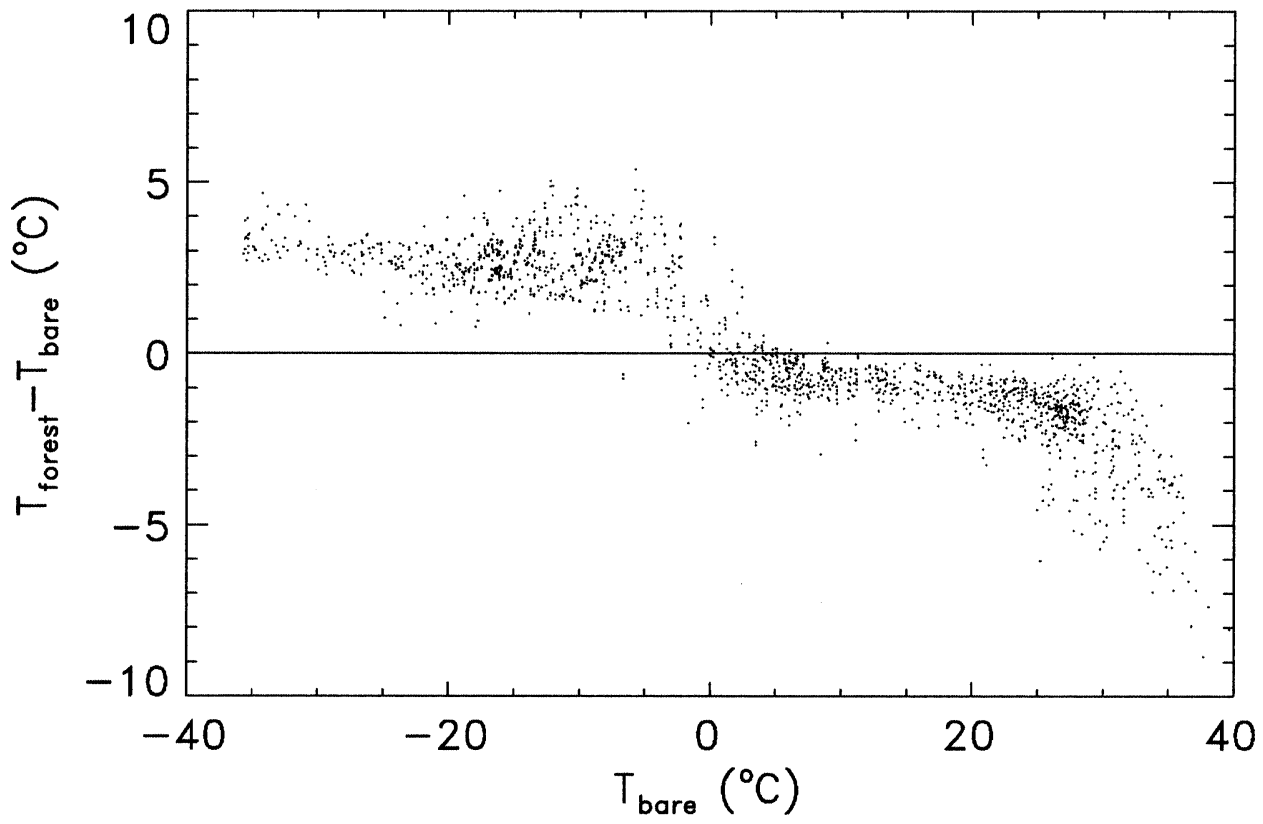

FIG. 4. Differences within gridboxes between average Mar surface temperatures for forests and bare ground. 
(a)
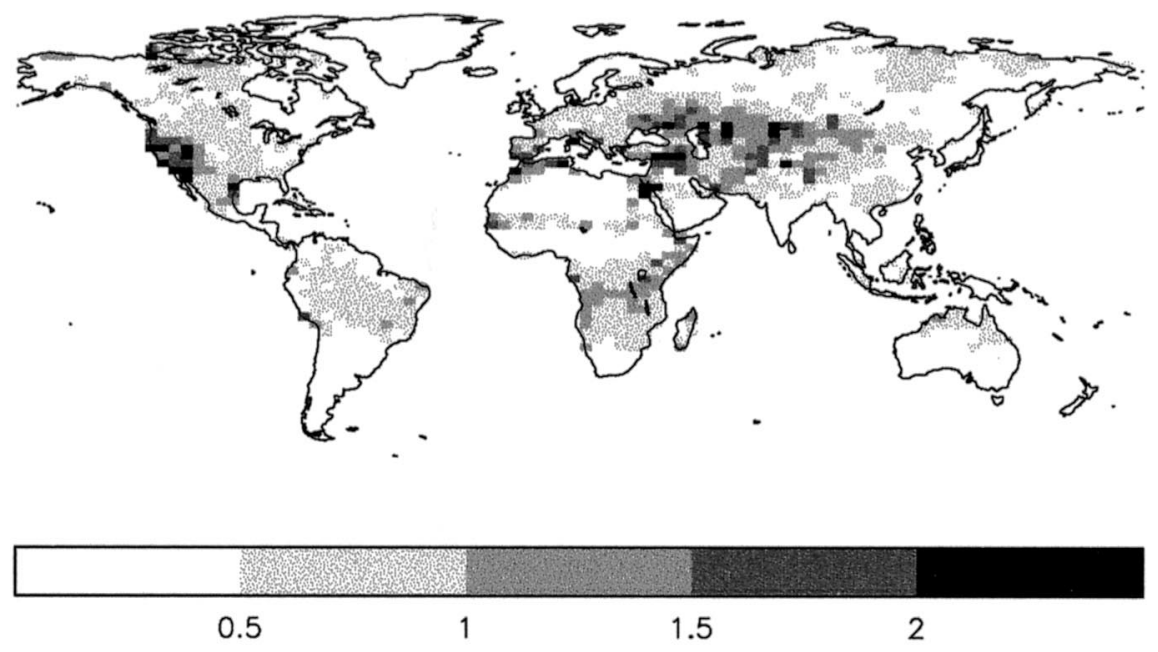

(b)
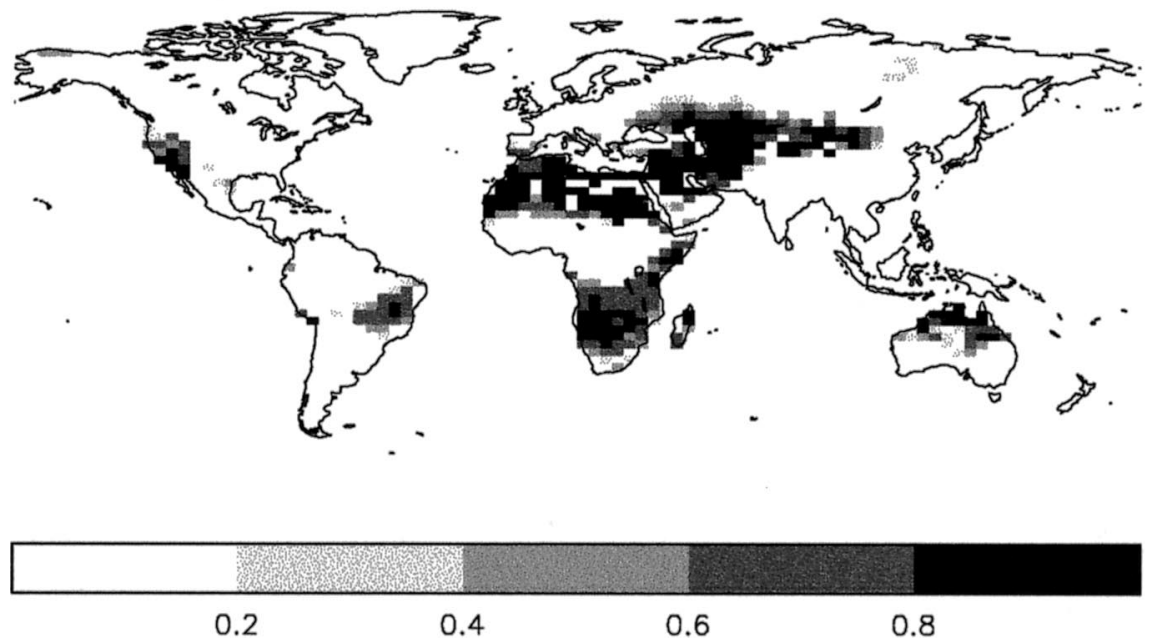

FIG. 5. (a) Subgrid standard deviation of tile surface temperatures for Jul. (b) Fractional soil moisture deficit in the surface layer.

precipitation to drive the model rather than coupling it to an atmospheric model. A rough prediction of the impact of aggregation on an offline simulation can be obtained from a simplified analysis of Eqs. (5) and (12). Neglecting heat fluxes into the ground and differences in upward longwave radiation between tiles gives the tile surface temperature as

$$
T_{* j}=T_{1}+\frac{g z_{1}}{c_{p}}+\frac{R_{N j} r_{a j} / \rho-L \psi_{j} \Delta q_{1}}{c_{p}+\mathrm{LD} \psi_{j}}
$$

in the absence of snowmelt, and taking a gridbox average gives

$$
\begin{aligned}
\overline{T_{*}}= & T_{1}+\frac{g z_{1}}{c_{p}}+\frac{1}{\rho} \sum_{j} \frac{\nu_{j} R_{N j} r_{a j}}{c_{p}+\mathrm{LD} \psi_{j}} \\
& -L \Delta q_{1} \sum_{j} \frac{\nu_{j} \psi_{j}}{c_{p}+\mathrm{LD} \psi_{j}} .
\end{aligned}
$$

For snow-free, unstressed vegetation there will be little contrast in $R_{N}$ and $\psi$ between tiles, and Eq. (25) gives 
(a)
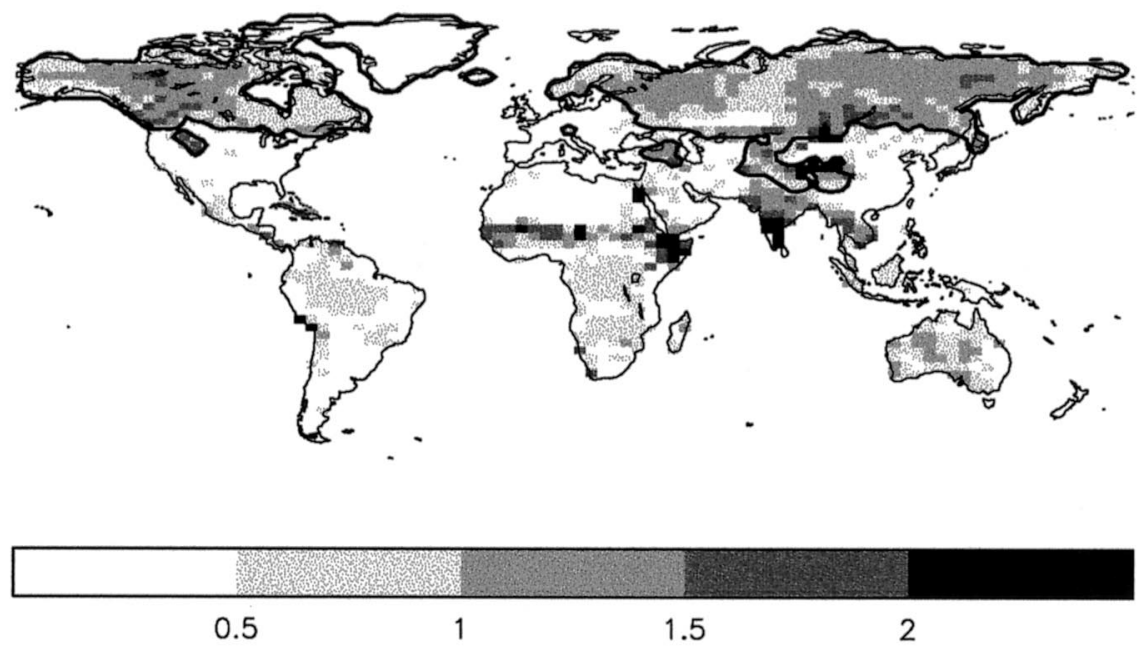

(b)
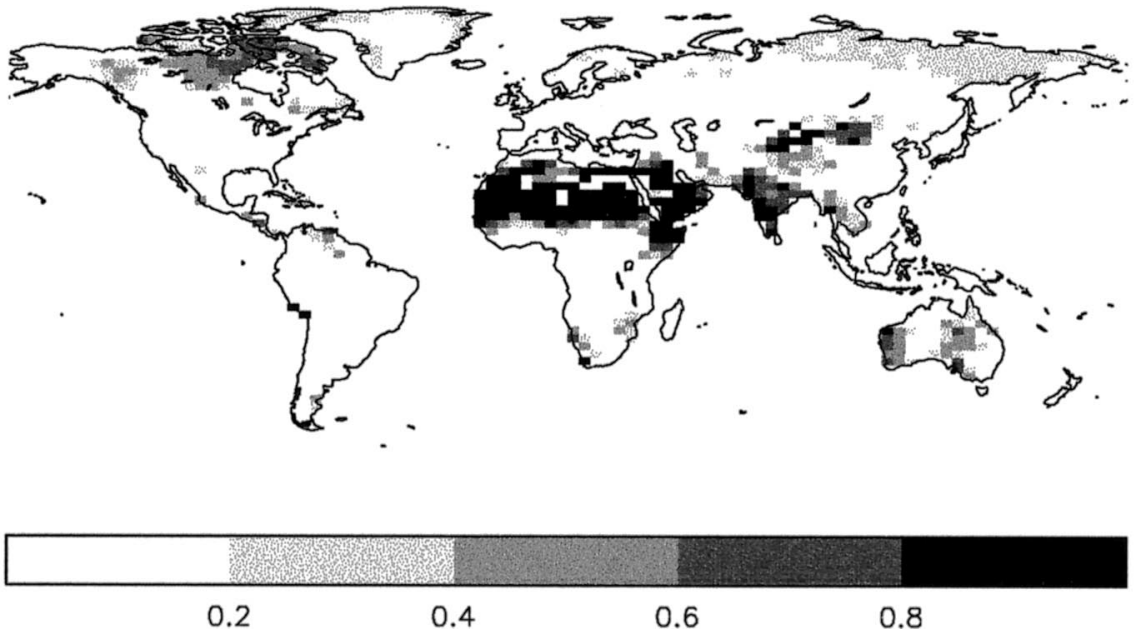

FIG. 6. As in Fig. 5, but for Mar. The heavy line in (a) shows the southern extent of snow cover.

$$
\begin{aligned}
\overline{T_{*}} \approx & T_{1}+\frac{g z_{1}}{c_{p}} \\
& +\frac{\overline{R_{N}}}{\rho\left(c_{p}+\mathrm{LD} \bar{\psi}\right)} \sum_{j} \nu_{j} r_{a j}-\frac{L \bar{\psi} \Delta q_{1}}{c_{p}+\mathrm{LD} \bar{\psi}},
\end{aligned}
$$

but the surface temperature in the aggregate model is

$T_{*}=T_{1}+\frac{g z_{1}}{c_{p}}+\frac{\overline{R_{N}}}{\rho\left(c_{p}+\mathrm{LD} \bar{\psi}\right)} r_{a}^{0}-\frac{L \bar{\psi} \Delta q_{1}}{c_{p}+\mathrm{LD} \bar{\psi}}$,

where $r_{a}^{0}$ is the aggregated aerodynamic resistance. Resistances combined in parallel give

$$
r_{a}^{0}=\left(\sum \frac{\nu_{j}}{r_{a j}}\right)^{-1}<\sum \nu_{j} r_{a j}
$$

and the tile model thus has a higher average surface temperature than the aggregate model when the net radiation is positive. Koster and Suarez (1992a) found this same result for the restricted case of two tiles with the same albedo. With snow cover, however, there are large differences between the albedos of tiles with tall vegetation and those without. Equation (25), with $\psi=1$ for snow, then gives 

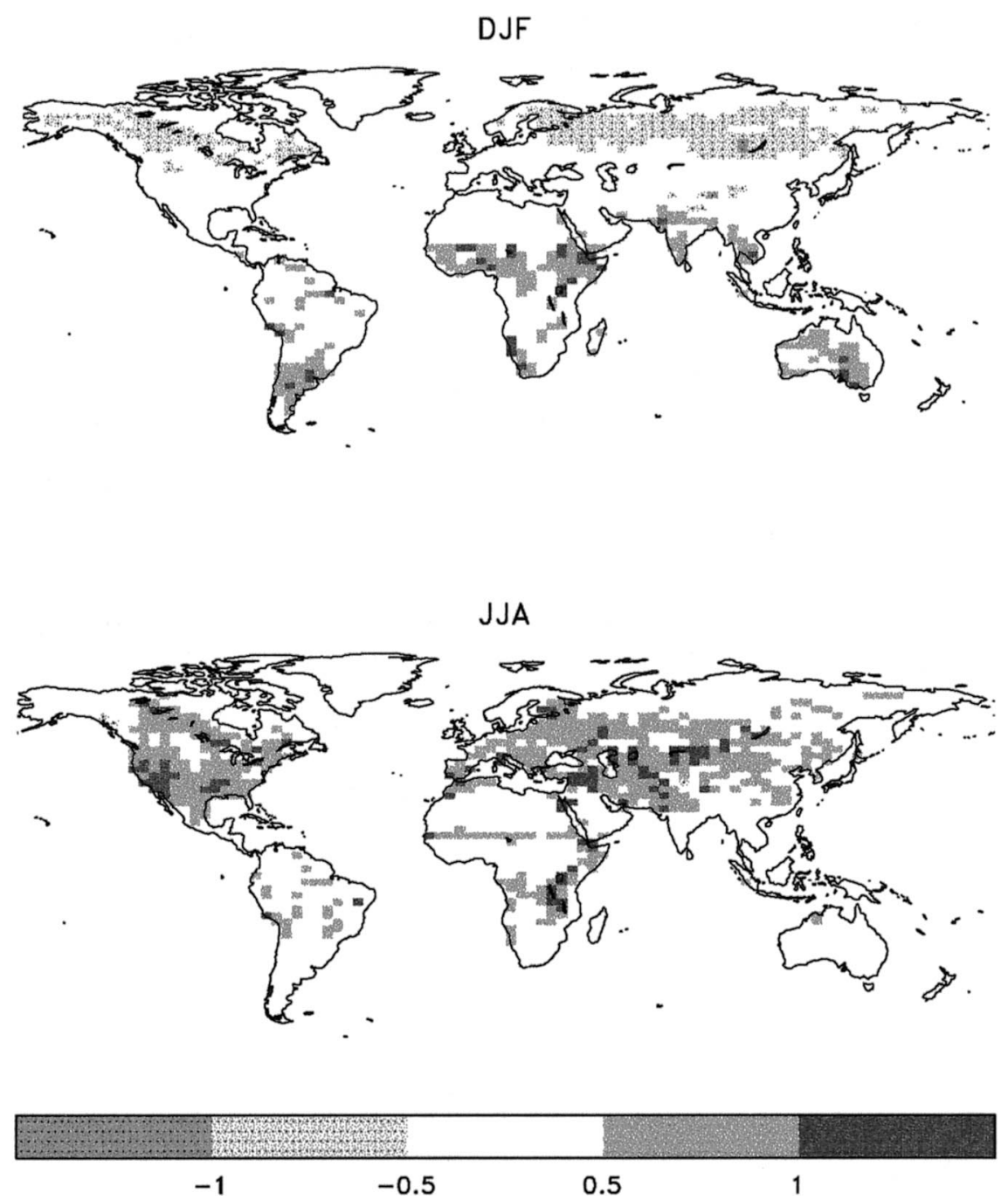

FIG. 7. Differences in average DJF and JJA surface temperatures between the tile model and the offline aggregate model. Positive values indicate gridboxes in which the tile model data are warmer.

$$
\begin{aligned}
\overline{T_{*}}= & T_{1}+\frac{g z_{1}}{c_{p}} \\
& +\frac{1}{\rho\left(c_{p}+\mathrm{LD}\right)} \sum_{j} \nu_{j} R_{N j} r_{a j}-\frac{L \Delta q_{1}}{c_{p}+\mathrm{LD}}
\end{aligned}
$$

for the tile model and

$$
T_{*}=T_{1}+\frac{g z_{1}}{c_{p}}+\frac{1}{\rho\left(c_{p}+\mathrm{LD}\right)} \overline{R_{N}} r_{a}^{0}-\frac{L \Delta q_{1}}{c_{p}+\mathrm{LD}}
$$

for the aggregate model. Since tall vegetation will have the highest net radiation and the lowest aerodynamic resistance, it is possible to have $\Sigma \nu_{j} R_{N j} r_{a j}<\overline{R_{N}} r_{a}^{0}$, and the tile model can have lower temperatures than the aggregate model for partially forested gridboxes with snow cover.

The tile model structure allows the introduction of "diagnostic" tiles with zero area that thus respond to but do not influence the model's meteorology; this fea- ture was used to run an offline aggregate model alongside the tile model in the GCM. The conclusions above are broadly confirmed by Fig. 7, which shows DJF and $\mathrm{JJA}$ differences in average surface temperatures between the coupled tile model and the offline aggregate model. The tile model data are generally warmer in JJA but show lower DJF temperatures over forested areas in high northern latitudes. Differences between the two models are small, only exceeding $1{ }^{\circ} \mathrm{C}$ for a few gridboxes.

\section{d. Influence of atmospheric feedbacks}

The discussion in section $3 \mathrm{c}$ relies on the downward radiation, air temperature, and humidity being the same for the tiled and aggregated models. This simplifies the analysis but may not given an accurate indication of the behavior of a GCM with an aggregated surface model because surface fluxes calculated offline do not influ- 

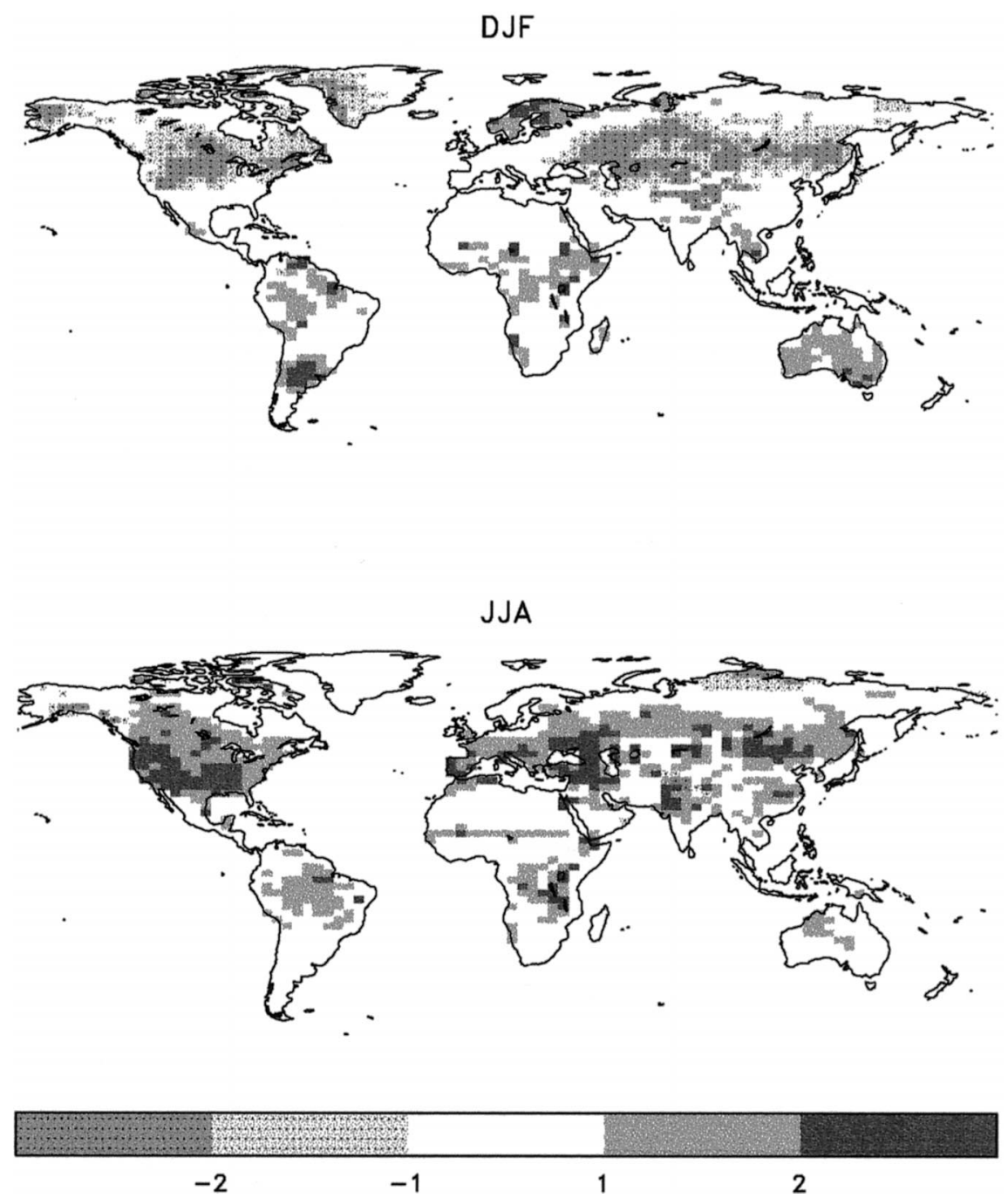

FIG. 8. Differences in average DJF and JJA surface temperatures between the tile model and the coupled aggregate model.

ence the atmosphere. When the aggregate model is fully coupled to the atmospheric model, feedbacks through the atmosphere can modify the differences between the surface models. Figure 8 compares the tile model and the coupled aggregate model. The differences show similar patterns to those shown in Fig. 7 but are amplified (note the change in scale), and the area of winter warming in the aggregate model is more extensive.

As noted by Koster and Suarez (1992a), the aggregate model gives greater evaporation; averaging the surface conductances gives moisture fluxes that are dominated by the less stressed parts of the gridbox. Increased evaporation in the aggregate model is recycled through an increase in precipitation over land. Higher humidities and increased cloud cover at low levels in the atmosphere decrease incoming solar radiation in the summer, leading to a cooling relative to the tile model, but can decrease the loss of longwave radiation from the surface in winter and give a warming. Regional averages from the simulation using the aggregate model are shown by crosses on Figs. 2 and 3. The aggregate model generally has a reduced annual temperature range at midlatitudes, decreased diurnal temperature range, increased precipitation, and decreased shortwave radiation in comparison with the tile model. Considering uncertainties in the surface radiative forcing and the climatology, it is not possible to show that the tile model gives a clear improvement in the simulated climate.

The influence of atmospheric feedbacks on the surface is illustrated in Fig. 9, which shows average annual cycles of daily maximum and minimum air temperatures, precipitation, and surface energy fluxes for a gridbox centered on $40^{\circ} \mathrm{N}, 108.75^{\circ} \mathrm{W}$ (Colorado). Results are shown for both the tile model (solid lines) and the aggregate model (dashed lines) coupled to the atmosphere. This gridbox has the pattern of winter cooling and summer warming of the tile model relative to the aggregate model characteristic of northern midlatitudes 

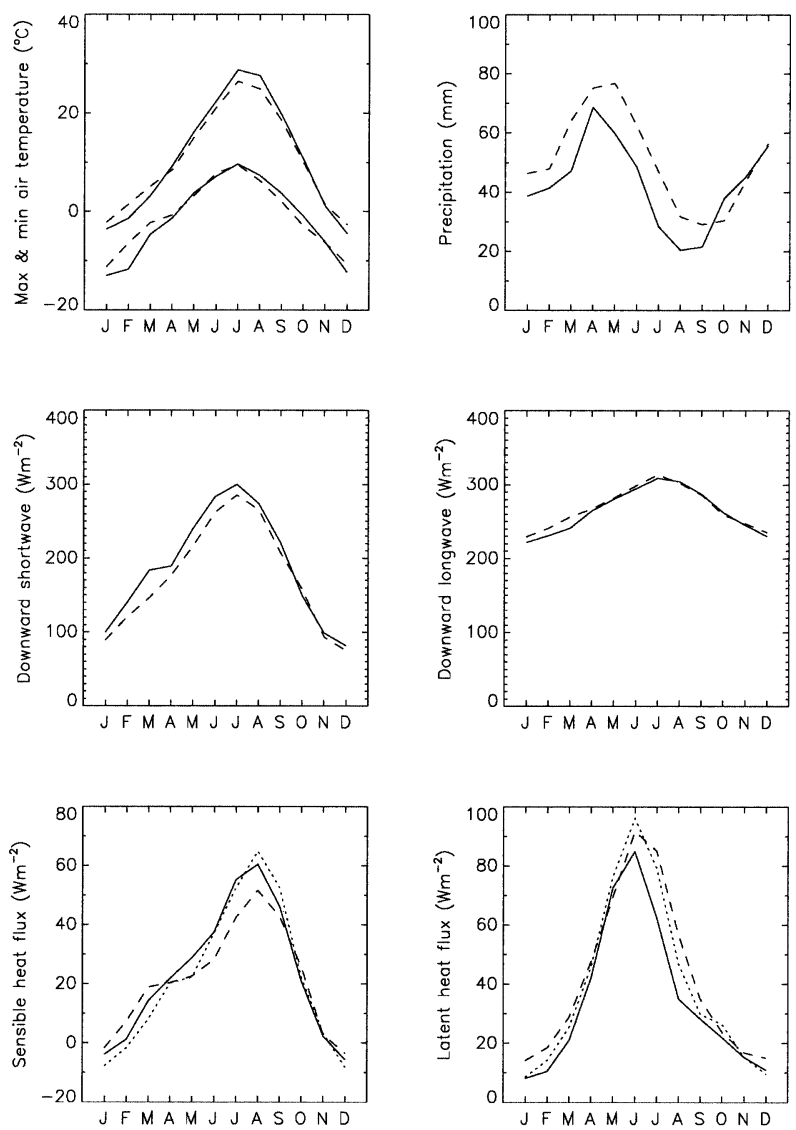

FIG. 9. Maximum and minimum daily air temperatures, precipitation, and surface energy fluxes for a gridbox in Colorado. Solid lines are from the simulation with the tile model, dashed lines from the coupled aggregate model and dotted lines (bottom panels) from the offline aggregate model.

shown in Fig. 8. Decreased surface evaporation and precipitation in the tile model lead to warmer and dryer conditions in the lower atmosphere with less low cloud cover during most of the year. As a result, downward shortwave fluxes are increased and longwave fluxes are decreased. This leads to an increase in summer maximum temperatures and a decrease in winter minimum temperatures that are reflected in the average temperatures. The offline aggregate model also shows differences from the tile model in surface sensible heat and moisture fluxes (dotted lines in Fig. 9), but air temperatures, precipitation, and downward radiative fluxes are not affected.

\section{Conclusions and discussion}

In addition to several other enhancements over the MOSES land surface scheme, MOSES 2 introduces a tiled representation of heterogeneous surfaces. Land gridboxes are characterized as mosaics of distinct surface types, and separate surface temperatures, sensible and latent heat fluxes, snow depths, and canopy moisture loads are calculated for each surface type. Coupled to the HadAM3 GCM, MOSES 2 simulates average surface air temperatures and diurnal temperature ranges that are in reasonable agreement with climatology, once the GCM's cloud cover has been adjusted to remove a bias in the solar radiation reaching the surface. Aggregating the surface parameters within gridboxes but still using the same meteorological forcing in an offline simulation gives slightly lower summer temperatures at midlatitudes and higher winter temperatures at high northern latitudes. When the aggregate model is coupled to the GCM, atmospheric feedbacks involving changes in radiative fluxes reaching the surface enhance these differences.

Although the choice of an aggregated or tiled surface representation certainly influences the simulated climate, the explicit representation of surface heterogeneity by tiling does not give a clear improvement in the simulation. The implementation of tiling in a GCM, however, makes the specification of surface parameters easier, provides potentially useful information on subgrid temperature and flux variations, and allows models of processes for distinctive surface types to be introduced in a more direct way than through effective parameters for mixed surfaces. Surface types for which improved models are being developed for use in MOSES 2 include vegetation canopies (Best 1998a; Best and Hopwood 2001; Essery et al. 2001), urban surfaces (Best 1998b), and coastal gridboxes containing both land and sea (N. Gedney 2001, personal communication). MOSES 2 has been implemented in the Met Office operational mesoscale model (Best et al. 2000), and an early version of the tile scheme is being used in a sitespecific model to add local detail to numerical weather forecasts (Best et al. 1997; Hopwood 1998).

Land surface schemes influence not only the climatology of GCMs but also their climate sensitivity (Cox et al. 1999; Crossley et al. 2000; Gedney et al. 2000). Future work will investigate the impact of MOSES 2 on climate change simulations.

Acknowledgments. This work was supported by the UK DEFRA Climate Prediction Programme under Contract PECD 7/12/37. The vegetation maps were prepared by Mike Dunderdale (Department of Geomatic Engineering, University College London). John Edwards, Nic Gedney, and Phil Hopwood provided useful advice. Jan Polcher and two anonymous reviewers made many useful comments on a draft of this paper.

\section{REFERENCES}

Arola, A., 1999: Parameterization of turbulent and mesoscale fluxes for heterogeneous surfaces. J. Atmos. Sci., 56, 584-598.

Avissar, R., and R. Pielke, 1989: A parameterization of heterogeneous land surfaces for atmospheric numerical models and its impact on regional meteorology. Mon. Wea. Rev., 117, 2113-2136.

Barker, H. W., G. L. Stephens, and Q. Fu, 1999: The sensitivity of 
domain-averaged solar fluxes to assumptions about cloud geometry. Quart. J. Roy. Meteor. Soc., 125, 2127-2152.

Best, M. J., 1998a: A model to predict surface temperatures. Bound.Layer Meteor., 88, 279-306.

_ 1998b: Representing urban areas in numerical weather prediction models. Preprints, Second Urban Environment Symp., Albuquerque, NM, Amer. Meteor. Soc., 148-151.

— change over a grass field site under stable conditions. Quart. J. Roy. Meteor. Soc., 127, 2033-2052.

,$- \ldots$, and S. D. Jackson, 1997: The tile surface exchange scheme: Performance within the site specific forecast model. Forecasting Research Tech. Rep. 220, Met Office, Bracknell, United Kingdom, 44 pp.

—, F. J. Bornemann, B. V. Chalcraft, and C. A. Wilson, 2000: Mesoscale model upgrade-Introduction of the land surface tile scheme (MOSES 2). Forecasting Research Tech. Rep. 341, Met Office, Bracknell, United Kingdom, 30 pp.

Betts, R. A., 2000: Offset of the potential carbon sink from boreal forestation by decreases in surface albedo. Nature, 408, 187190.

Beven, K., 1997: TOPMODEL: A critique. Hydrol. Processes, 11, 1069-1085.

Blyth, E. M., 1995: Using a simple SVAT to describe the effect of scale on aggregation. Bound.-Layer Meteor., 72, 2113-2136.

Claussen, M., 1991: Estimation of areally-averaged surface fluxes. Bound.-Layer Meteor., 54, 387-410.

Covey, C., K. M. AchutaRao, M. Forino, P. J. Gleckler, K. E. Taylor, and M. F. Wehner, 2002: Intercomparison of climate data sets as a measure of observational uncertainty. PCMDI Rep. 69, Lawrence Livermore National Laboratory, 38 pp. [Available online at www-pcmdi.llnl.gov/pcmdi/pubs/pdf/rpt69.pdf.]

Cox, P. M., 2001: Description of the "TRIFFID" dynamic global vegetation model. Hadley Centre Tech. Note 24, Met Office, Bracknell, United Kingdom, 17 pp. [Available online at www.metoffice.gov. uk/research/hadleycentre/pubs/HCTN/HCTN_24.pdf.]

_ C. Huntingford, and R. J. Harding, 1998: A canopy conductance and photosynthesis model for use in a GCM land surface scheme. J. Hydrol., 212, 79-94.

— R. A. Betts, C. B. Bunton, R. L. H. Essery, P. R. Rowntree, and J. Smith, 1999: The impact of new land surface physics on the GCM simulation of climate and climate sensitivity. Climate Dyn., 15, 183-203.

— — C C. D. Jones, S. A. Spall, and I. J. Totterdell, 2000: Acceleration of global warming due to carbon-cycle feedbacks in a coupled climate model. Nature, 408, 184-187.

Crossley, J. F., J. Polcher, P. M. Cox, N. Gedney, and S. Planton, 2000: Uncertainties linked to land-surface processes in climate change simulations. Climate Dyn., 16, 949-961.

Cusack, S., A. Slingo, J. M. Edwards, and M. Wild, 1998: The radiative impact of a simple aerosol climatology on the Hadley Centre atmospheric GCM. Quart. J. Roy. Meteor. Soc., 124, $2517-2526$.

— J. J. M. Edwards, and R. Kershaw, 1999: Estimating the subgrid variance of saturation, and its parameterization for use in a GCM cloud scheme. Quart. J. Roy. Meteor. Soc., 125, 3057-3076.

Desborough, C. E., 1999: Surface energy balance complexity in GCM land surface models. Climate Dyn., 15, 389-403.

_- A. J. Pitman, and A. McAvaney, 2001: Surface energy balance complexity in GCM land surface models. Part II: Coupled simulations. Climate Dyn., 17, 615-626.

Dolman, A. J., and D. Gregory, 1992: The parameterization of rainfall interception in GCMs. Quart. J. Roy. Meteor. Soc., 118, 455469.

Essery, R. L. H., 1997: Modelling fluxes of momentum, sensible heat and latent heat over heterogeneous snow cover. Quart. J. Roy. Meteor. Soc., 123, 1867-1883.

- M. J. Best, and P. M. Cox, 2001: MOSES 2.2 technical documentation. Hadley Centre Tech. Note 30, Met Office, Bracknell,
United Kingdom, 30 pp. [Available online at www.metoffice. gov.uk/research/hadleycentre/pubs/HCTN/HCTN_30.pdf.]

Gedney, N., P. M. Cox, H. Douville, J. Polcher, and P. J. Valdes, 2000: Characterizing GCM land surface schemes to understand their responses to climate change. J. Climate, 13, 3066-3079.

Girard, C., and Y. Delage, 1990: Stable schemes for nonlinear vertical diffusion in atmospheric circulation models. Mon. Wea. Rev., 118, 737-745.

Hansen, M. C., R. S. DeFries, J. R. G. Townshend, and R. Sohlberg, 2000: Global land cover classification at $1 \mathrm{~km}$ spatial resolution using a classification tree approach. Int. J. Remote Sens., 21, $1331-1364$.

Hogan, R. J., and A. J. Illingworth, 2000: Deriving cloud overlap statistics from radar. Quart. J. Roy. Meteor. Soc., 126, 29032909.

Hopwood, W. P., 1998: The implementation of local surface characteristics within a site-specific model for short range forecasting. Preprints, 16th Conf. on Weather Analysis and Forecasting, Phoenix, AZ, Amer. Meteor. Soc., 487-489.

Klink, K., 1995: Surface aggregation and subgrid-scale climate. Int. J. Climatol., 15, 1219-1240.

Koster, R. D., and M. J. Suarez, 1992a: A comparative analysis of two land surface heterogeneity representations. J. Climate, 5, 1379-1390.

_ and $-1992 \mathrm{~b}$ : Modelling the land surface boundary in climate models as a composite of independent vegetation stands. J. Geophys. Res., 97, 2697-2715.

—_, and — 1996: The influence of land surface moisture retention on precipitation statistics. J. Climate, 9, 2551-2567.

Louis, J.-F., 1979: A parametric model of vertical eddy fluxes in the atmosphere. Bound.-Layer Meteor., 17, 187-202.

Marshall, S. E., 1989: A physical parameterization of snow albedo for use in climate models. NCAR Cooperative Thesis 123, National Center for Atmospheric Research, Boulder, CO, $161 \mathrm{pp}$.

Mason, P. J., 1988: The formation of areally-averaged roughness lengths. Quart. J. Roy. Meteor. Soc., 114, 399-420.

Mölders, N., A. Raabe, and G. Tetzlaff, 1996: A comparison of two strategies on land surface heterogeneity used in a mesoscale beta meteorological model. Tellus, 48A, 733-749.

Molod, A., and H. Salmun, 2002: A global assessment of the mosaic approach to modeling land surface heterogeneity. J. Geophys. Res., 107, 4217, doi:10.1029/2001JD000588.

New, M., M. Hulme, and P. Jones, 1999: Representing twentiethcentury space-time climate variability. Part I: Development of a 1961-90 mean monthly terrestrial climatology. J. Climate, 12, $829-856$

Polcher, J., and Coauthors, 1998: A proposal for a general interface between land-surface schemes and general circulation models. Global Planet. Change, 19, 261-276.

Pomeroy, J. W., and K. Dion, 1996: Winter radiation extinction and reflection in a boreal pine canopy: Measurements and modelling. Hydrol. Processes, 10, 1591-1608.

Pope, V. D., M. L. Gallani, P. R. Rowntree, and R. A. Stratton, 2000: The impact of new physical parameterizations in the Hadley Centre Climate Model: HadAM3. Climate Dyn., 16, 123-146.

Sellers, P. J., 1985: Canopy reflectance, photosynthesis and transpiration. Int. J. Remote Sens., 6, 1335-1372.

— S. O. Los, C. J. Tucker, C. O. Justice, D. A. Dazlich, G. J. Collatz, and D. A. Randall, 1996a: A revised land surface parameterization ( $\mathrm{SiB} 2)$ for atmospheric GCMs. Part II: The generation of global fields of terrestrial biophysical parameters from satellite data. J. Climate, 9, 706-737.

__ , and Coauthors, 1996b: The ISLSCP Initiative I global datasets: Surface boundary conditions and atmospheric forcings for landatmosphere studies. Bull. Amer. Meteor. Soc., 77, 1987-2005.

Taylor, C. M., and D. B. Clark, 2001: The diurnal cycle and African easterly waves: A land surface perspective. Quart. J. Roy. Meteor. Soc., 127, 845-867.

Thornley, J. H. M., and I. R. Johnson, 1990: Plant and Crop Modelling. Oxford University Press, 669 pp. 
van den Hurk, B. J. J. M., P. Viterbo, A. C. M. Beljaars, and A. K. Betts, 2000: Offline validation of the ERA40 surface scheme. ECMWF Tech. Memo. 295, European Centre for Medium-Range Weather Forecasts, Reading, United Kingdom, 42 pp.

Verseghy, D. L., N. A. McFarlane, and M. Lazare, 1993: CLASSA Canadian land surface scheme for GCMs. II. Vegetation mode and coupled runs. Int. J. Climatol., 13, 347-370.

Viterbo, P., and A. K. Betts, 1999: Impact on ECMWF forecasts of changes to the albedo of the boreal forests in the presence of snow. J. Geophys. Res., 104, 27 803-27 810.

Webb, M. J., S. Senior, S. Bony, and J.-J. Morcrette, 2001: Combining ERBE and ISCCP data to assess clouds in the Hadley Centre ECMWF and LMD atmospheric climate models. Climate Dyn. 17, 905-922.
Wild, M., 2000: Absorption of solar energy in cloudless and cloudy atmospheres over Germany and in GCMs. Geophys. Res. Lett., 27, 959-962.

— - A. Ohmura, H. Gilgen, and E. Roeckner, 1995: Validation of general circulation model radiative fluxes using surface observations. J. Climate, 8, 1309-1324.

Wilson, M. F., and A. Henderson-Sellers, 1985: A global archive of land cover and soils data for use in general circulation models. J. Climatol., 5, 119-143.

Wiscombe, W. J., and S. G. Warren, 1980: A model for the spectral albedo of snow. I: Pure snow. J. Atmos. Sci., 37, 2712-2733.

Wood, N., and P. Mason, 1991: The influence of static stability on the effective roughness lengths for momentum and heat transfer. Quart. J. Roy. Meteor. Soc., 117, 1025-1056. 